AZIZBAyov E.I., MEHRALIYEV Y.T.

\title{
NONLOCAL INVERSE BOUNDARY-VALUE PROBLEM FOR A 2D PARABOLIC EQUATION WITH INTEGRAL OVERDETERMINATION CONDITION
}

\begin{abstract}
This article studies a nonlocal inverse boundary-value problem for a two-dimensional secondorder parabolic equation in a rectangular domain. The purpose of the article is to determine the unknown coefficient and the solution of the considered problem. To investigate the solvability of the inverse problem, we transform the original problem into some auxiliary problem with trivial boundary conditions. Using the contraction mappings principle, existence and uniqueness of the solution of an equivalent problem are proved. Further, using the equivalency, the existence and uniqueness theorem of the classical solution of the original problem is obtained.

Key words and phrases: inverse problem, two-dimensional parabolic equation, Fourier method, classical solution, overdetermination condition.
\end{abstract}

Baku State University, AZ1148, Baku, Azerbaijan

E-mail: eazizbayov@bsu.edu.az (Azizbayov E.I.), yashar_aze@mail.ru (Mehraliyev Y.T.)

\section{INTRODUCTION AND FORMULATION OF THE INVERSE PROBLEM}

In the present paper, we consider an inverse boundary-value problem for a two-dimensional parabolic equation in a rectangular domain. The main goal of this article is to prove the existence and uniqueness of a classical solution of an inverse boundary-value problem.

The inverse problems arise in many different areas of mathematical modeling types, such as mineral exploration, biology, medicine, seismology, desalination of seawater, movement of liquid in a porous medium, financial market behavior, etc. Fundamentals of the theory and practice of research of inverse problems were established and developed in the pioneering works of Tikhonov [18], Lavrent'ev [15], Ivanov [10], Romanov [17], Denisov [3, 4]. Recently, there have been many studies of inverse problems for 1D parabolic and other types of equations. A more detailed bibliography and a classification of problems may be found in $[1,2,6,7,11,12]$.

Problems of the solvability of inverse problems for a two-dimensional heat equation is extensively studied by many authors, see, for example, Ismailov [5], Ivanchov [8,9], Kabanikhin [13], Kinash [14], Zaynullov [19], and others. But the statement of the problem and the proof techniques used in this study are different from representations in these papers.

Motivated by these works, we study in this paper the existence and uniqueness of a classical solution for the following inverse problem: in the domain $D_{T}=\bar{Q}_{x y} \times[0, T]$, where $Q_{x y}=$ $\{(x, y): 0<x<1,0<y<1\}$, consider a two-dimensional parabolic equation

$$
u_{t}(x, y, t)-c(t)\left(u_{x x}(x, y, t)+u_{y y}(x, y, t)\right)=a(t) u(x, y, t)+f(x, y, t),(x, y, t) \in D_{T},
$$


with the nonlocal condition

$$
u(x, y, 0)+\delta u(x, y, T)=\varphi(x, y), \quad(x, y) \in \bar{Q}_{x y}
$$

the boundary conditions

$$
\begin{gathered}
u(0, y, t)=u_{x}(1, y, t)=0, \quad 0 \leq y \leq 1,0 \leq t \leq T, \\
u_{y}(x, 0, t)=u(x, 1, t)=0, \quad 0 \leq x \leq 1,0 \leq t \leq T,
\end{gathered}
$$

and the overdetermination condition

$$
u\left(x_{0}, y_{0}, t\right)+\int_{0}^{1} \int_{0}^{1} K(x, y) u(x, y, t) d x d y=h(t), \quad 0 \leq t \leq T, 0<x_{0}, y_{0}<1,
$$

where $\delta \geq 0$ is known number, $\left(x_{0}, y_{0}\right) \in Q_{x y}$ is some fixed point, $0<c(t), f(x, y, t), \varphi(x, y)$, $h(t)$ are given functions, $u(x, y, t)$ and $a(t)$ are unknown functions.

Definition 1. The pair $\{u(x, y, t), a(t)\}$ is said to be a classical solution of the problem (1)-(5), if the functions $u(x, y, t) \in C^{2,2,1}\left(D_{T}\right)$ and $a(t) \in C[0, T]$ satisfy equation (1) in $D_{T}$, and the conditions (2)-(5) in the classical (usual) sense.

To investigate the existence and uniqueness of the classical solution of problem (1)-(5), we prove the following theorem.

Theorem 1. Suppose that $\delta \geq 0, f(x, y, t) \in C\left(D_{T}\right), \varphi(x, y) \in C\left(\bar{Q}_{x y}\right), K(x, y) \in L_{1}\left(Q_{x y}\right)$, $h(t) \in C^{1}[0, T], h(t) \neq 0,0 \leq t \leq T$ and the compatibility condition

$$
\varphi\left(x_{0}, y_{0}\right)+\int_{0}^{1} \int_{0}^{1} K(x, y) \varphi(x, y) d x d y=h(0)+\delta h(T)
$$

holds true. Then the problem of finding a classical solution of (1)-(5) is equivalent to the problem of determining the functions $u(x, y, t) \in C^{2,2,1}\left(D_{T}\right)$ and $a(t) \in C[0, T]$, satisfying (1)-(4), and the condition

$$
\begin{gathered}
h^{\prime}(t)-c(t)\left(u_{x x}\left(x_{0}, y_{0}, t\right)+u_{y y}\left(x_{0}, y_{0}, t\right)+\int_{0}^{1} \int_{0}^{1} K(x, y)\left(u_{x x}(x, y, t)+u_{y y}(x, y, t)\right) d x d y\right) \\
=a(t) h(t)+f\left(x_{0}, y_{0}, t\right)+\int_{0}^{1} \int_{0}^{1} K(x, y) f(x, y, t) d x d y, \quad 0 \leq t \leq T .
\end{gathered}
$$

Proof. Let $\{u(x, y, t), a(t)\}$ be the classical solution of problem (1)-(5). Then from equation (1), we have

$$
\begin{aligned}
& \frac{d}{d t}\left(u\left(x_{0}, y_{0}, t\right)+\int_{0}^{1} \int_{0}^{1} K(x, y) u(x, y, t) d x d y\right) \\
& -c(t)\left(u_{x x}\left(x_{0}, y_{0}, t\right)+u_{y y}\left(x_{0}, y_{0}, t\right)+\int_{0}^{1} \int_{0}^{1} K(x, y)\left(u_{x x}(x, y, t)+u_{y y}(x, y, t)\right) d x d y\right)
\end{aligned}
$$




$$
\begin{aligned}
& =a(t)\left(u\left(x_{0}, y_{0}, t\right)+\int_{0}^{1} \int_{0}^{1} K(x, y) u(x, y, t) d x d y\right) \\
& +f\left(x_{0}, y_{0}, t\right)+\int_{0}^{1} \int_{0}^{1} K(x, y) f(x, y, t) d x d y, \quad 0 \leq t \leq T .
\end{aligned}
$$

Differentiating both sides of (6) with respect to $t$ gives

$$
\frac{d}{d t}\left(u\left(x_{0}, y_{0}, t\right)+\int_{0}^{1} \int_{0}^{1} K(x, y) u(x, y, t) d x d y\right)=h^{\prime}(t), \quad 0 \leq t \leq T .
$$

From (8), taking into account (5) and (9), we arrive at (7).

Now, assume that $\{u(x, y, t), a(t)\}$ is a solution to the problem (1)-(4), (7). Then from (7) and (8), we get

$$
\begin{aligned}
& \frac{d}{d t}\left(u\left(x_{0}, y_{0}, t\right)+\int_{0}^{1} \int_{0}^{1} K(x, y) u(x, y, t) d x d y-h(t)\right) \\
& =a(t)\left(u\left(x_{0}, y_{0}, t\right)+\int_{0}^{1} \int_{0}^{1} K(x, y) u(x, y, t) d x d y-h(t)\right), \quad 0 \leq t \leq T .
\end{aligned}
$$

Using (2) and the compatibility condition (6), we obtain the following relation

$$
\begin{aligned}
& u\left(x_{0}, y_{0}, 0\right)+\int_{0}^{1} \int_{0}^{1} K(x, y) u(x, y, 0) d x d y-h(0) \\
& +\delta\left(u\left(x_{0}, y_{0}, T\right)+\int_{0}^{1} \int_{0}^{1} K(x, y) u(x, y, T) d x d y-h(T)\right) \\
& =u\left(x_{0}, y_{0}, 0\right)+\delta u\left(x_{0}, y_{0}, T\right)+\int_{0}^{1} \int_{0}^{1} K(x, y)(u(x, y, 0)+u(x, y, T)) d x d y \\
& -(h(0)+\delta h(T))=\varphi\left(x_{0}, y_{0}\right)+\int_{0}^{1} \int_{0}^{1} K(x, y) \varphi(x, y) d x d y-(h(0)+\delta h(T))=0 .
\end{aligned}
$$

It is clear that the general solution of equation (10) has the form

$$
u\left(x_{0}, y_{0}, t\right)+\int_{0}^{1} \int_{0}^{1} K(x, y) u(x, y, t) d x d y-h(t)=c e^{\int^{t} a(\tau) d \tau},
$$

where $c$ is an arbitrary constant.

Hence, using (11), we find

$$
c\left(1+\delta e^{-\int_{0}^{T} a(\tau) d \tau}\right)=0
$$


By virtue of $\delta \geq 0$, from (13), we obtain that $c=0$. Setting $c=0$ in (12), we conclude that

$$
u\left(x_{0}, y_{0}, t\right)+\int_{0}^{1} \int_{0}^{1} K(x, y) u(x, y, t) d x d y-h(t)=0, \quad 0 \leq t \leq T
$$

Hence, the condition (5) is satisfied. The proof is complete.

\section{SOLVABILITY OF THE INVERSE BOUNDARY-VALUE PROBLEM}

We seek the first component $u(x, y, t)$ of classical solution $\{u(x, y, t), a(t)\}$ of the problem (1)-(4), (7) in the form

$$
\begin{aligned}
u(x, y, t) & =\sum_{k=1}^{\infty} \sum_{n=1}^{\infty} u_{k, n}(t) \sin \lambda_{k} x \cos \gamma_{n} y, \\
\lambda_{k} & =\frac{\pi}{2}(2 k-1), \gamma_{n}=\frac{\pi}{2}(2 n-1), k, n=1,2, \ldots,
\end{aligned}
$$

where

$$
u_{k, n}(t)=4 \int_{0}^{1} \int_{0}^{1} u(x, y, t) \sin \lambda_{k} x \cos \gamma_{n} y d x d y
$$

Applying the formal scheme of the Fourier method, from (1) and (2), we have

$$
\begin{gathered}
u_{k, n}^{\prime}(t)+\left(\lambda_{k}^{2}+\gamma_{n}^{2}\right) c(t) u_{k, n}(t)=F_{k, n}(t ; u, a), \quad 0 \leq t \leq T, \\
u_{k, n}(0)+\delta u_{k, n}(T)=\varphi_{k, n}, \quad k, n=1,2, \ldots,
\end{gathered}
$$

where

$$
F_{k, n}(t ; u, a)=f_{k, n}(t)+a(t) u_{k, n}(t),
$$

$f_{k, n}(t)=4 \int_{0}^{1} \int_{0}^{1} f(x, y, t) \sin \lambda_{k} x \cos \gamma_{n} y d x d y, \quad \varphi_{k, n}=4 \int_{0}^{1} \int_{0}^{1} \varphi(x, y) \sin \lambda_{k} x \cos \gamma_{n} y d x d y$

Solving problem (15), (16), we find

$$
\begin{aligned}
u_{k, n}(t)= & \frac{\varphi_{k, n} e^{-\int_{0}^{t} \mu_{k, n}^{2} c(s) d s}}{1+\delta e^{-\int_{0}^{T} \mu_{k, n}^{2} c(s) d s}}+\int_{0}^{t} F_{k, n}(\tau ; u, a) e^{-\int_{\tau}^{t} \mu_{k, n}^{2} c(s) d s} d \tau \\
- & \frac{\delta e^{-\int_{0}^{T} \mu_{k, n}^{2} c(s) d s}}{1+\delta e^{-\int_{0}^{T} \mu_{k, n}^{2} c(s) d s}} \int_{0}^{T} F_{k, n}(\tau ; u, a) e^{-\int_{\tau}^{t} \mu_{k, n}^{2} c(s) d s} d \tau,
\end{aligned}
$$

where

$$
\mu_{k, n}^{2}=\lambda_{k}^{2}+\gamma_{n}^{2}
$$


Substituting the expressions $u_{k, n}(t)(k, n=1,2, \ldots)$ described by (17) into (14), to determine the first component of the solution (1)-(4), (7), we obtain

$$
\begin{aligned}
u(x, y, t)=\sum_{k=1}^{\infty} \sum_{n=1}^{\infty}\{ & \frac{\varphi_{k, n} e^{-\int_{0}^{t} \mu_{k, n}^{2} c(s) d s}}{1+\delta e^{-\int_{0}^{T} \mu_{k, n}^{2} c(s) d s}}+\int_{0}^{t} F_{k, n}(\tau ; u, a) e^{-\int_{\tau}^{t} \mu_{k, n}^{2} c(s) d s} d \tau \\
& \left.-\frac{\delta e^{-\int_{0}^{T} \mu_{k, n}^{2} c(s) d s}}{1+\delta e^{-\int_{0}^{T} \mu_{k, n}^{2} c(s) d s}} \int_{0}^{T} F_{k, n}(\tau ; u, a) e^{-\int_{\tau}^{t} \mu_{k, n}^{2} c(s) d s} d \tau\right\} \sin \lambda_{k} x \cos \gamma_{n} y .
\end{aligned}
$$

Further from (7), taking into account $h(t) \neq 0$, we get

$$
\begin{aligned}
a(t)=[h(t)]^{-1}\left\{h^{\prime}(t)\right. & -\left(f\left(x_{0}, y_{0}, t\right)+\int_{0}^{1} \int_{0}^{1} K(x, y) f(x, y, t) d x d y\right) \\
& \left.-c(t) \sum_{k=1}^{\infty} \sum_{n=1}^{\infty} u_{k, n}(t) p_{k, n}\right\},
\end{aligned}
$$

where

$$
p_{k, n}=\mu_{k, n}^{2}\left(\sin \lambda_{k} x_{0} \cos \gamma_{n} y_{0}+\int_{0}^{1} \int_{0}^{1} K(x, y) \sin \lambda_{k} x \cos \gamma_{n} y d x d y\right) .
$$

Next, substituting the expressions $u_{k, n}(t)(k, n=1,2, \ldots)$ represented by (17) into (19), to find the second component of the solution (1)-(4), (7), we have

$$
\begin{aligned}
& a(t)=[h(t)]^{-1}\left\{h^{\prime}(t)-\left(f\left(x_{0}, y_{0}, t\right)+\int_{0}^{1} \int_{0}^{1} K(x, y) f(x, y, t) d x d y\right)\right. \\
&-c(t) \sum_{k=1}^{\infty} \sum_{n=1}^{\infty}\left[\frac{\varphi_{k, n} e^{-\int_{0}^{t} \mu_{k, n}^{2} c(s) d s}}{1+\delta e^{-\int_{0}^{T} \mu_{k, n}^{2} c(s) d s}+\int_{0}^{t} F_{k, n}(\tau ; u, a) e^{-\int_{\tau}^{t} \mu_{k, n}^{2} c(s) d s} d \tau}\right. \\
&\left.\left.-\frac{\delta e^{-\int_{0}^{T} \mu_{k, n}^{2} c(s) d s}}{1+\delta e^{-\int_{0}^{T} \mu_{k, n}^{2} c(s) d s}} \int_{0}^{T} F_{k, n}(\tau ; u, a) e^{-\int_{\tau}^{t} \mu_{k, n}^{2} c(s) d s} d \tau\right] p_{k, n}\right\} .
\end{aligned}
$$

Thus, the solution of problem (1)-(4), (7) was reduced to the solution by systems (18), (20) with respect to unknown functions $u(x, y, t)$ and $a(t)$.

Proceeding from the definition of the solution of the problem (1)-(4), (7) the following statement is proved.

Lemma 1. If $\{u(x, y, t), a(t)\}$ is any solution of (1)-(4), (7) then the functions

$$
u_{k, n}(t)=4 \int_{0}^{1} \int_{0}^{1} u(x, y, t) \sin \lambda_{k} x \cos \gamma_{n} y d x d y, \quad k, n=1,2, \ldots,
$$

satisfy the system (17) on the interval $[0, T]$. 
Proof. Let $\{u(x, y, t), a(t)\}$ be any solution of problem (1)-(4), (7). Multiplying both sides of the equation (1) by function $4 \sin \lambda_{k} x \cos \gamma_{n} y \quad(k, n=1,2, \ldots)$ and integrating both sides with respect to $x$ and $y$ from 0 to 1 , and using relationships

$$
\begin{aligned}
& 4 \int_{0}^{1} \int_{0}^{1} u_{t}(x, y, t) \sin \lambda_{k} x \cos \gamma_{n} y d x d y=\frac{d}{d t}\left(4 \int_{0}^{1} \int_{0}^{1} u(x, y, t) \sin \lambda_{k} x \cos \gamma_{n} y d x d y\right)=u_{k, n}^{\prime}(t), \\
& 4 \int_{0}^{1} \int_{0}^{1}\left(u_{x x}(x, y, t)+u_{y y}(x, y, t)\right) \sin \lambda_{k} x \cos \gamma_{n} y d x d y \\
& \quad=-\left(\lambda_{k}^{2}+\gamma_{n}^{2}\right)\left(4 \int_{0}^{1} \int_{0}^{1} u(x, y, t) \sin \lambda_{k} x \cos \gamma_{n} y d x d y\right)=-\left(\lambda_{k}^{2}+\gamma_{n}^{2}\right) u_{k, n}(t), \quad k, n=1,2, \ldots,
\end{aligned}
$$

we get that the equation (15) is satisfied.

Similarly, from (2) we obtain that condition (16) is satisfied. Thus, $u_{k, n}(t), k, n=1,2, \ldots$, is a solution to the problem (15), (16). Hence, it straightforward follows that the functions $u_{k, n}(t)$, $k, n=1,2, \ldots$, satisfy on $[0, T]$ system (17). Thus the lemma is proved.

Obviously, if

$$
u_{k, n}(t)=4 \int_{0}^{1} \int_{0}^{1} u(x, y, t) \sin \lambda_{k} x \cos \gamma_{n} y d x d y, \quad k, n=1,2, \ldots
$$

is a solution to system (17), then the functions

$$
u(x, y, t)=\sum_{k=1}^{\infty} \sum_{n=1}^{\infty} u_{k, n}(t) \sin \lambda_{k} x \cos \gamma_{n} y,
$$

and $a(t)$ is a solution of system (18), (20).

From Lemma 1 it follows the next assertion.

Corollary 1. Suppose that system (18), (20) has a unique solution. Then the problem (1)-(4), (7), couldn't have more than one solution, in other words, if problem (1)-(4), (7) has a solution, then it is a unique.

In order to study the problem (1)-(4), (7), we consider the following spaces. Let $B_{2, T}^{3}$ denote the set of all functions of the form

$$
u(x, y, t)=\sum_{k=1}^{\infty} \sum_{n=1}^{\infty} u_{k, n}(t) \sin \lambda_{k} x \cos \gamma_{n} y, \quad \lambda_{k}=\frac{\pi}{2}(2 k-1), \quad \gamma_{n}=\frac{\pi}{2}(2 n-1), \quad k, n=1,2, \ldots,
$$

considered in domain $D_{T}$, where the functions $u_{k, n}(t), k, n=1,2, \ldots$, are continuous on $[0, T]$, and satisfy the condition

$$
\left\{\sum_{k=1}^{\infty} \sum_{n=1}^{\infty}\left(\mu_{k, n}^{3}\left\|u_{k, n}(t)\right\|_{C[0, T]}\right)^{2}\right\}^{\frac{1}{2}}<+\infty
$$


The norm in the space $B_{2, T}^{3}$ is defined as follows

$$
\|u(x, y, t)\|_{B_{2, T}^{3}}=\left\{\sum_{k=1}^{\infty} \sum_{n=1}^{\infty}\left(\mu_{k, n}^{3}\left\|u_{k, n}(t)\right\|_{C[0, T]}\right)^{2}\right\}^{\frac{1}{2}} .
$$

We denote by $E_{T}^{3}$ the topological product of $B_{2, T}^{3} \times C[0, T]$. The norm of the element $z=$ $\{u, a\}$ is determined by the formula

$$
\|z\|_{E_{T}^{3}}=\|u(x, y, t)\|_{B_{2, T}^{3}}+\|a(t)\|_{C[0, T]} .
$$

It is known [16] that the spaces $B_{2, T}^{3}$ and $E_{T}^{3}$ are Banach spaces.

Now, consider the operator

$$
\Phi(u, a)=\left\{\Phi_{1}(u, a), \Phi_{2}(u, a)\right\}
$$

in the space $E_{T}^{3}$, where

$$
\begin{gathered}
\Phi_{1}(u, a)=\tilde{u}(x, y, t)=\sum_{k=1}^{\infty} \sum_{n=1}^{\infty} \tilde{u}_{k, n}(t) \sin \lambda_{k} x \cos \gamma_{n} y, \\
\Phi_{2}(u, a)=\tilde{a}(t),
\end{gathered}
$$

and the functions $\tilde{u}_{k, n}(t), k, n=1,2, \ldots, \tilde{a}(t)$ are equal to the right-hand sides of (17), (20) respectively.

It is easy to see that

$$
\begin{gathered}
1+\delta e^{-\int_{0}^{T} \frac{\lambda_{k}^{2} \beta(s) d s}{1+\lambda_{k}^{2} \alpha(s)}} \geq 1 \\
\mu_{k, n}^{3} \leq\left(\lambda_{k}^{2}+\gamma_{k}^{2}\right)\left(\lambda_{k}+\gamma_{n}\right)=\lambda_{k}^{3}+\lambda_{k}^{2} \gamma_{n}+\gamma_{k}^{2} \lambda_{k}+\gamma_{n}^{3}, \\
\int_{0}^{T}\left|f_{k, n}(\tau)\right| d \tau \leq \sqrt{T}\left(\int_{0}^{T}\left|f_{k, n}(\tau)\right|^{2} d \tau\right)^{\frac{1}{2}}, \\
\left|p_{k, n}\right|=\left(1+\int_{0}^{1} \int_{0}^{1}|K(x, y)| d x d y\right) \mu_{k, n}^{2} \equiv p \mu_{k, n}^{2} .
\end{gathered}
$$

Taking into consideration these relations, we have

$$
\begin{aligned}
& \left\{\sum_{n=1}^{\infty} \sum_{k=1}^{\infty}\left(\mu_{k, n}^{3}\left\|\tilde{u}_{k, n}(t)\right\|_{C[0, T]}\right)^{2}\right\}^{\frac{1}{2}} \leq 3\left(\sum_{n=1}^{\infty} \sum_{k=1}^{\infty}\left(\lambda_{k}^{3}\left|\varphi_{k, n}\right|\right)^{2}\right)^{\frac{1}{2}} \\
& +3\left(\sum_{n=1}^{\infty} \sum_{k=1}^{\infty}\left(\lambda_{k}^{2} \gamma_{n}\left|\varphi_{k, n}\right|\right)^{2}\right)^{\frac{1}{2}}+3\left(\sum_{n=1}^{\infty} \sum_{k=1}^{\infty}\left(\lambda_{k} \gamma_{n}^{2}\left|\varphi_{k, n}\right|\right)^{2}\right)^{\frac{1}{2}}+3\left(\sum_{n=1}^{\infty} \sum_{k=1}^{\infty}\left(\gamma_{n}^{3}\left|\varphi_{k, n}\right|\right)^{2}\right)^{\frac{1}{2}} \\
& +3(1+\delta)\left[\sqrt { T } \left(\left(\int_{0}^{T} \sum_{n=1}^{\infty} \sum_{k=1}^{\infty}\left(\lambda_{k}^{3}\left|f_{k, n}(\tau)\right|\right)^{2} d \tau\right)^{\frac{1}{2}}+\left(\int_{0}^{T} \sum_{n=1}^{\infty} \sum_{k=1}^{\infty}\left(\lambda_{k}^{2} \gamma_{n}\left|f_{k, n}(\tau)\right|\right)^{2} d \tau\right)^{\frac{1}{2}}\right.\right. \\
& \left.+\left(\int_{0}^{T} \sum_{n=1}^{\infty} \sum_{k=1}^{\infty}\left(\lambda_{k} \gamma_{n}^{2}\left|f_{k, n}(\tau)\right|\right)^{2} d \tau\right)^{\frac{1}{2}}+\left(\int_{0}^{T} \sum_{n=1}^{\infty} \sum_{k=1}^{\infty}\left(\gamma_{n}^{3}\left|f_{k, n}(\tau)\right|\right)^{2} d \tau\right)^{\frac{1}{2}}\right) \\
& \left.+T\|a(t)\|_{C[0, T]}\left(\sum_{k=1}^{\infty} \sum_{k=1}^{\infty}\left(\mu_{k, n}^{3}\left\|u_{k, n}(t)\right\|_{C[0, T]}\right)^{2}\right)^{\frac{1}{2}}\right]
\end{aligned}
$$




$$
\begin{aligned}
& \|\tilde{a}(t)\|_{C[0, T]} \\
& \leq\left\|[h(t)]^{-1}\right\|_{C[0, T]}\left\{\left\|h^{\prime}(t)-\left(f\left(x_{0}, y_{0}, t\right)+\int_{0}^{1} \int_{0}^{1} K(x, y) f(x, y, t) d x d y\right)\right\|_{C[0, T]}\right. \\
& +p\|c(t)\|_{C[0, T]}\left(\sum_{k=1}^{\infty} \sum_{k=1}^{\infty} \mu_{k}^{-2}\right)^{\frac{1}{2}}\left[\left(\sum_{n=1}^{\infty} \sum_{k=1}^{\infty}\left(\lambda_{k}^{3}\left|\varphi_{k, n}\right|\right)^{2}\right)^{\frac{1}{2}}+\left(\sum_{n=1}^{\infty} \sum_{k=1}^{\infty}\left(\lambda_{k}^{2} \gamma_{n}\left|\varphi_{k, n}\right|\right)^{2}\right)^{\frac{1}{2}}\right. \\
& +\left(\sum_{n=1}^{\infty} \sum_{k=1}^{\infty}\left(\lambda_{k} \gamma_{n}^{2}\left|\varphi_{k, n}\right|\right)^{2}\right)^{\frac{1}{2}}+\left(\sum_{n=1}^{\infty} \sum_{k=1}^{\infty}\left(\gamma_{n}^{3}\left|\varphi_{k, n}\right|\right)^{2}\right)^{\frac{1}{2}} \\
& +(1+\delta) \sqrt{T}\left(\left(\int_{0}^{T} \sum_{n=1}^{\infty} \sum_{k=1}^{\infty}\left(\lambda_{k}^{3}\left|f_{k, n}(\tau)\right|\right)^{2} d \tau\right)^{\frac{1}{2}}+\left(\int_{0}^{T} \sum_{n=1}^{\infty} \sum_{k=1}^{\infty}\left(\lambda_{k}^{2} \gamma_{n}\left|f_{k, n}(\tau)\right|\right)^{2} d \tau\right)^{\frac{1}{2}}\right. \\
& \left.+\left(\int_{0}^{T} \sum_{n=1}^{\infty} \sum_{k=1}^{\infty}\left(\lambda_{k} \gamma_{n}^{2}\left|f_{k, n}(\tau)\right|\right)^{2} d \tau\right)^{\frac{1}{2}}+\left(\int_{0}^{T} \sum_{n=1}^{\infty} \sum_{k=1}^{\infty}\left(\gamma_{n}^{3}\left|f_{k, n}(\tau)\right|\right)^{2} d \tau\right)^{\frac{1}{2}}\right) \\
& \left.\left.+(1+\delta) T\|a(t)\|_{C[0, T]}\left(\sum_{k=1}^{\infty} \sum_{k=1}^{\infty}\left(\mu_{k, n}^{3}\left\|u_{k, n}(t)\right\|_{C[0, T]}\right)^{2}\right)^{\frac{1}{2}}\right]\right\}
\end{aligned}
$$

Assume that the data for the problem (1)-(4), (7) satisfy the following conditions:

(A) $\varphi(x, y), \varphi_{x}(x, y), \varphi_{x x}(x, y), \varphi_{y}(x, y), \varphi_{x y}(x, y), \varphi_{y y}(x, y) \in C\left(\bar{Q}_{x y}\right)$, $\varphi_{x x y}(x, y), \varphi_{x y y}(x, y), \varphi_{x x x}(x, y), \varphi_{y y y}(x, y) \in L_{2}\left(Q_{x y}\right)$, $\varphi(0, y)=\varphi_{x}(1, y)=\varphi_{x x}(0, y)=0,0 \leq y \leq 1$, $\varphi_{y}(x, 0)=\varphi(x, 1)=\varphi_{y y}(x, 1)=0,0 \leq x \leq 1 ;$

(B) $f(x, y, t), f_{x}(x, y, t), f_{x x}(x, y, t), f_{y}(x, y, t), f_{x y}(x, y, t), f_{x y}(x, y, t) \in C\left(D_{T}\right)$, $f_{x x y}(x, y, t), f_{x y y}(x, y, t), f_{x x x}(x, y, t), f_{y y y}(x, y, t) \in L_{2}\left(D_{T}\right)$, $f(0, y, t)=f_{x}(1, y, t)=f_{x x}(0, y, t)=0,0 \leq y \leq 1,0 \leq t \leq T$, $f_{y}(x, 0, t)=f(x, 1, t)=f_{y y}(x, 1, t)=0,0 \leq x \leq 1,0 \leq t \leq T ;$

(C) $\delta \geq 0, K(x, y) \in L_{1}\left(Q_{x y}\right), 0<c(t) \in C[0, T], h(t) \in C^{1}[0, T], h(t) \neq 0,0 \leq t \leq T$.

Then, from (21) and (22), respectively, we obtain

$$
\begin{aligned}
\|\tilde{u}(x, y, t)\|_{B_{2, T}^{3}} & \leq A_{1}(T)+B_{1}(T)\|a(t)\|_{C[0, T]}\|u(x, y, t)\|_{B_{2, T}^{3},}, \\
\|\tilde{a}(t)\|_{C[0, T]} & \leq A_{2}(T)+B_{2}(T)\|a(t)\|_{C[0, T]}\|u(x, y, t)\|_{B_{2, T}^{3}},
\end{aligned}
$$

where

$$
\begin{aligned}
A_{1}(T)=3\left\|\varphi_{x x x}(x, y)\right\|_{L_{2}\left(Q_{x y}\right)} & +3\left\|\varphi_{x y y}(x, y)\right\|_{L_{2}\left(Q_{x y}\right)}+3\left\|\varphi_{x x y}(x, y)\right\|_{L_{2}\left(Q_{x y}\right)} \\
& +3\left\|\varphi_{y y y}(x, y)\right\|_{L_{2}\left(Q_{x y}\right)}+(1+\delta) \sqrt{T} 3\left(\left\|f_{x x x}(x, y, t)\right\|_{L_{2}\left(D_{T}\right)}\right. \\
& +3\left\|f_{x y y}(x, y, t)\right\|_{L_{2}\left(D_{T}\right)}+3\left\|f_{x x y}(x, y, t)\right\|_{L_{2}\left(D_{T}\right)} \\
& \left.+3\left\|f_{x x x}(x, y, t)\right\|_{L_{2}\left(D_{T}\right)}+3\left\|f_{y y y}(x, y, t)\right\|_{L_{2}\left(D_{T}\right)}\right), \\
B_{1}(T) & =3(1+\delta) T,
\end{aligned}
$$




$$
\begin{aligned}
A_{2}(T) & =\left\|[h(t)]^{-1}\right\|_{C[0, T]}\left\{\|\left(h^{\prime}(t)-\left(f\left(x_{0}, y_{0}, t\right)+\int_{0}^{1} \int_{0}^{1} K(x, y) f(x, y, t) d x d y\right) \|_{C[0, T]}\right.\right. \\
& +p\|c(t)\|_{C[0, T]}\left(\sum_{k=1}^{\infty} \sum_{k=1}^{\infty} \mu_{k}^{-2}\right)^{\frac{1}{2}}\left[\left\|\varphi_{x x x}(x, y)\right\|_{L_{2}\left(Q_{x y}\right)}+\left\|\varphi_{x y y}(x, y)\right\|_{L_{2}\left(Q_{x y}\right)}\right. \\
& +\left\|\varphi_{x x y}(x, y)\right\|_{L_{2}\left(Q_{x y}\right)}+\left\|\varphi_{y y y}(x, y)\right\|_{L_{2}\left(Q_{x y}\right)}+(1+\delta) \sqrt{T}\left(\left\|f_{x x x}(x, y, t)\right\|_{L_{2}\left(D_{T}\right)}\right. \\
& \left.\left.\left.+\left\|f_{x y y}(x, y, t)\right\|_{L_{2}\left(D_{T}\right)}+\left\|f_{x x y}(x, y, t)\right\|_{L_{2}\left(D_{T}\right)}\right)\right]\right\} \\
& \left.\left.\left.+\left\|f_{x x x}(x, y, t)\right\|_{L_{2}\left(D_{T}\right)}+\left\|f_{y y y}(x, y, t)\right\|_{L_{2}\left(D_{T}\right)}\right)\right]\right\} \\
B_{2}(T) & =\left\|[h(t)]^{-1}\right\|_{C[0, T]} p\|c(t)\|_{C[0, T]}\left(\sum_{k=1}^{\infty} \sum_{k=1}^{\infty} \mu_{k}^{-2}\right)^{\frac{1}{2}}(1+\delta) T .
\end{aligned}
$$

From inequalities (23) and (24) we conclude

$$
\|\tilde{u}(x, y, t)\|_{B_{2, T}^{3}}+\|\tilde{a}(t)\|_{C[0, T]} \leq A(T)+B(T)\|a(t)\|_{C[0, T]}\|u(x, t)\|_{B_{2, T}^{3}},
$$

where

$$
A(T)=A_{1}(T)+A_{2}(T), \quad B(T)=B_{1}(T)+B_{2}(T) .
$$

Let $K_{R}$ denote the closed ball of radius $R=A(T)+2$ centered at zero in $E_{T}^{3}$.

Theorem 2. Let the conditions $(A)-(C)$ and the condition

$$
B(T)(A(T)+2)^{2}<1
$$

be fulfilled. Then problem (1)-(4), (7) has a unique solution in the ball $K_{R}$.

Proof. Let us consider in the space $E_{T}^{3}$ the equation

$$
z=\Phi z
$$

where $z=\{u, a\}$. The components $\Phi_{i}(u, a), i=1,2$, of operator $\Phi(u, a)$ defined by the right side of equations (18), (20), respectively. Now, consider the operator $\Phi(u, a)$ in the ball $K_{R}$ of the space $E_{T}^{3}$.

Similar to (25) we obtain that for any $z, z_{1}, z_{2} \in K_{R}$ the following inequalities hold

$$
\begin{gathered}
\|\Phi z\|_{E_{T}^{3}} \leq A(T)+B(T)\|p(t)\|_{C[0, T]}\|u(x, y, t)\|_{B_{2, T}^{3}} \leq A(T)+B(T)(A(T)+2)^{2} \\
\left\|\Phi z_{1}-\Phi z_{2}\right\|_{E_{T}^{3}} \leq B(T) R\left(\left\|u_{1}(x, y, t)-u_{2}(x, y, t)\right\|_{B_{2, T}^{3}}+\left\|a_{1}(t)-a_{2}(t)\right\|_{C[0, T]}\right) .
\end{gathered}
$$

Then by (26), from estimates (28) and (29) it is clear that the operator $\Phi z$ acts in a ball $K_{R}$ and satisfy the conditions of the contraction mapping principle. Therefore the operator $\Phi z$ has a unique fixed point $\{u, a\}$ in the ball $K_{R}$, which is a unique solution of equation (27), i.e., $\{u, a\}$ is a unique solution of the systems (18), (20) in the ball $K_{R}$.

The function $u(x, y, t)$ as an element of the space $E_{T}^{3}$ is continuous and has continuous derivatives $u_{x}(x, y, t), u_{x x}(x, y, t), u_{y}(x, y, t), u_{x y}(x, y, t), u_{y y}(x, y, t)$ in $D_{T}$. 
From the equation (15) it is clear that

$$
\begin{gathered}
u_{k, n}^{\prime}(t)+\left(\lambda_{k}^{2}+\gamma_{n}^{2}\right) c(t) u_{k, n}(t)=F_{k, n}(t ; u, a), \quad 0 \leq t \leq T, \\
\left\{\sum_{n=1}^{\infty} \sum_{k=1}^{\infty}\left(\mu_{k, n}\left\|u_{k, n}^{\prime}(t)\right\|_{C[0, T]}\right)^{2}\right\}^{\frac{1}{2}} \leq \sqrt{2}\|c(t)\|_{C[0, T]}\|u(x, y, t)\|_{B_{2, T}^{3}} \\
+\|\| f_{x}(x, y, t)+f_{y}(x, y, t)+p(t)\left(u_{x}(x, y, t)+u_{y}(x, y, t)\right)\left\|_{C[0, T]}\right\|_{L_{2}\left(Q_{x y}\right)} .
\end{gathered}
$$

Thus $u_{t}(x, y, t)$ is continuous in $D_{T}$.

It is not hard to verify that equation (1) and conditions (2)-(4), (7) are satisfied in the usual sense. Thus, the solution of the problem (1)-(4), (7) is a pair of functions $\{u(x, t), a(t)\}$. By virtue of the Lemma 1, it is unique in the ball $K_{R}$. Theorem has been proved.

Thus, by Theorem 1 and Theorem 2, we arrive at the following main result.

Theorem 3. Assume that all conditions of Theorem 2 and compatibility condition

$$
\varphi\left(x_{0}, y_{0}\right)+\int_{0}^{1} \int_{0}^{1} K(x, y) \varphi(x, y) d x d y=h(0)+\delta h(T)
$$

hold. Then problem (1)-(5) has a unique classical solution in the ball $K_{R}$ for sufficiently small values of $T$.

Acknowledgements. The authors would like to thank the anonymous referees for their careful reading of this paper and constructive suggestions that have improved the quality of our work.

\section{REFERENCES}

[1] Azizbayov E., Mehraliyev Y. Solvability of nonlocal inverse boundary-value problem for a second-order parabolic equation with integral conditions. Electron. J. Differential Equations 2017, 2017 (125), 1-14.

[2] Azizbayov E. The nonlocal inverse problem of the identification of the lowest coefficient and the right-hand side in a second-order parabolic equation with integral conditions. Bound. Value Probl. 2019, 2019 (11), 1-19. doi:10.1186/s13661-019-1126-z

[3] Denisov A.M. Elements of the theory of inverse problems. Inverse and Ill-posed Problems Series, VSP, Utrecht, 1999.

[4] Denisov A.M. Introduction to the theory of inverse problems. Moscow University Press, Moscow, 1994. (in Russian)

[5] Ismailov M.I., Erkovan S., Huseynova A.A. Fourier series analysis of a time-dependent perfusion coefficient determination in a 2D bioheat transfer process. Trans. Natl. Acad. Sci. Azerb. Ser. Phys.-Tech. Math. Sci. 2018, 38 (4), 70-78.

[6] Ivanchov M.I. Inverse problem for equations of parabolic type. Mathematical Studies, Monograph Series, 10. VNTL Publishers, Lviv, 2003.

[7] Ivanchov M.I., Saldina N.V. Inverse problem for a parabolic equation with strong power degeneration. Ukrainian Math. J. 2006, 58 (11), 1685-1703. doi:10.1007/s11253-006-0162-x

[8] Ivanchov M.I., Vlasov V. Inverse problem for a two-dimensional strongly degenerate heat equation. Electron. J. Differential Equations 2018, 2018 (77), 1-17. doi:10.30970/vmm.2018.85.120-131 
[9] Ivanchov M.I., Kinash N.E. Inverse problem for the heat-conduction equation in a rectangular domain. Ukrainian Math. J. 2018, 69 (12), 1865-1876. doi:10.1007/s11253-018-1476-1

[10] Ivanov V.K., Vasin V.V., Tanana V.P. Theory of linear ill-posed problems and its applications. Nauka, Moscow, 1978. (in Russian)

[11] Kabanikhin S. Definitions and examples of inverse and ill-posed problems. J. Inv. Ill-Posed Problems 2008, 16 (4), 317-357. doi:10.1515/JIIP.2008.069

[12] Kabanikhin S.I. Inverse and Ill-posed Problems. Theory and Applications. de Gruyter, Berlin, 2012.

[13] Kabanikhin S.I., Shishlenin M.A. Two-dimensional analogs of the equations of Gelfand, Levitan, Krein, and Marchenko. Eurasian J. Math. Comput. Appl 2015, 3 (2), 70-99. doi:10.32523/2306-3172-2015-3-2-70-99

[14] Kinash N.Y. An inverse problem for a 2D parabolic equation with nonlocal overdetermination condition. Carpathian Math. Publ. 2016, 8 (1), 107-117. doi:10.15330/cmp.8.1.107-117

[15] Lavrent'ev M.M., Romanov V.G., Shishatskii S.P. Ill-Posed Problems of Mathematical Physics and Analysis. American Mathematical Society, 1986.

[16] Mehraliyev Y.T. On an inverse boundary value problem for a second-order elliptic equation with the integral condition. Visnyk of the Lviv Univ. Ser. Mech. Math. 2012, (77), 145-156.

[17] Romanov V.G. Inverse Problems of Mathematical Physics. Moscow, 1984. (in Russian)

[18] Tikhonov A.N. On stability of inverse problems. Dokl. Akad. Nauk SSSR 1943, 39 (5), 195-198. (in Russian)

[19] Zaynullov A.R. An inverse problem for two-dimensional equations of finding the thermal conductivity of the initial distribution. J. Samara State Tech. Univ., Ser. Phys. Math. Sci. 2015, 19 (4), 667-679. doi:10.14498/vsgtu1451

Received 29.04.2019

Азізбайов Е.І., Мехралієв Ю.Т. Нелокальна обернена крайова задача для двовимірного параболічного рівняння з інтегральною переозначеною умовою // Карпатські матем. публ. - 2020. - Т.12, №1. - C. 23-33.

В роботі досліджено нелокальну обернену крайову задачу для двовимірного параболічного рівняння другого порядку у прямокутній області. Метою цієї статті $є$ визначення невідомого коефіцієнта та розв'язку вказаної задачі. Щоб дослідити роз'язність оберненої задачі, ми перетворюємо оригінальну задачу у деяку допоміжну задачу з тривіальними крайовими умовами. Використовуючи принцип стискаючих відображень, доведено існування і єдиність розв'язку для еквівалентної задачі. Використовуючи еквівалентність, отримано теорему про існування і єлиність класичного розв' язку оригінальної задачі.

Ключові слова і фрази: обернена задача, двовимірне параболічне рівняння, метод Фур'є, класичний розв' язок, переозначена умова. 